\title{
Retract 0.005 and propose using JASP, instead
}

\author{
Jose D. Perezgonzalez (Massey University, New Zealand)
}

Dolores Frías-Navarro (University of Valencia, Spain)

Seeking to address the lack of research reproducibility due to the high rate of false positives in the literature, Benjamin et al. $(2017 \mathrm{a}, \mathrm{b})$ propose a pragmatic solution which "aligns with the training undertaken by many researchers, and might quickly achieve broad acceptance" (also Savehn, 2017): to use a stricter 0.005 standard for statistical significance when claiming evidence of new discoveries.

The proposal is subject to several constrains in its application: (1) to claims of discovery of new effects (thus, not necessarily to replication studies); (2) when using null hypothesis significance testing (arguably Fisher's approach, perhaps even Neyman-Pearson's, but excluding other $p$-valuegenerating approaches such as resampling); (3) in fields with too flexible standards (namely $5 \%$ or above); (4) when the prior odds of alternative-to-null hypothesis is in the range 1-to-5, to 1-to-40 (stricter standards are required with lower odds); (5) for researcher's consumption (thus, not a standard for journal rejection, although "journals can help transition to the new statistical significance threshold"; also, "journals editors and funding institutions could easily enforce the proposal", Wagenmakers, 2017; and "its implementation only requires journal editors to agree on the new threshold", Machery, 2017); (6) while still keeping findings with probability up to $5 \%$ as suggestive (and meriting publication if so "properly labelled"); (7) despite many of the proponents believing that the proposal is nonsense, anyway (that is, it is a quick fix, not a credible one; also loannidis in Resnick, 2017; Wagenmakers, 2017; Wagenkamers and Gronau, 2017; Easwaran, 2017).

The main analyses supporting the proposal were the following: (a) a calibration of $p$-values to Bayes factors under certain plausible alternatives (their Fig. 1); (b) an estimated false positive rate under certain plausible prior odds of alternative-to-null hypotheses as a function of power (their Fig. 2); and (c) a "critical mass of researchers now endors[ing] this change" (a.k.a., the 72 co-authors). Meanwhile, the proposal downplays the costs due to increasing sample size in order to ensure enough research power, the potential increase in false negatives and misconduct, and the existence of alternative solutions well known by, at least, some of the authors (despite Machery's, 2017, claim to the contrary).

Notwithstanding its potential impact, Benjamin et al.'s (2017) proposal is not recognizant of the entire engine of science (our Fig.1), which has motivated an even larger mass of authors to offer their counter-arguments.

From Philosophy of science, Mayo (2017a), in particular, provides important arguments against the philosophical standing of Benjamin et al.'s proposal. Quoting Greenland et al. (2016), Mayo asserts that whether $p$-values exaggerate the evidence against the null hypothesis depends on the philosophical background within which such claim is made: It may seem so from a Bayesian perspective, but both from a frequentist and an error statistics perspective, it is the Bayes factor which exaggerates the evidence (also 2017e). "I find it especially troubling" - she continues - "to 
spoze an error statistician...ought to use a Bayes Factor as the future gold standard for measuring his error statistical tool...even though Bayes Factors don't control or measure error probabilities" (2017b). Furthermore, Mayo pinpoints the (old) fallacy of transposing the conditional, whereby the (error) probability of a test is confused with the (posterior) probability of a belief (also Trafimow et al., 2017). And despite "60 years (sic) old...demonstrations [showing] that with reasonable tests and reasonable prior probabilities, the disparity vanishes...they still mean different things" (2017c). In particular, "in an adequate account [of severity testing], the improbability of a claim must be distinguished from its having been poorly tested. (You need to be able to say things like, 'it's plausible, but that's a lousy test of it.')" (2017d). And "the method for such checking is significance tests!" (2017b).

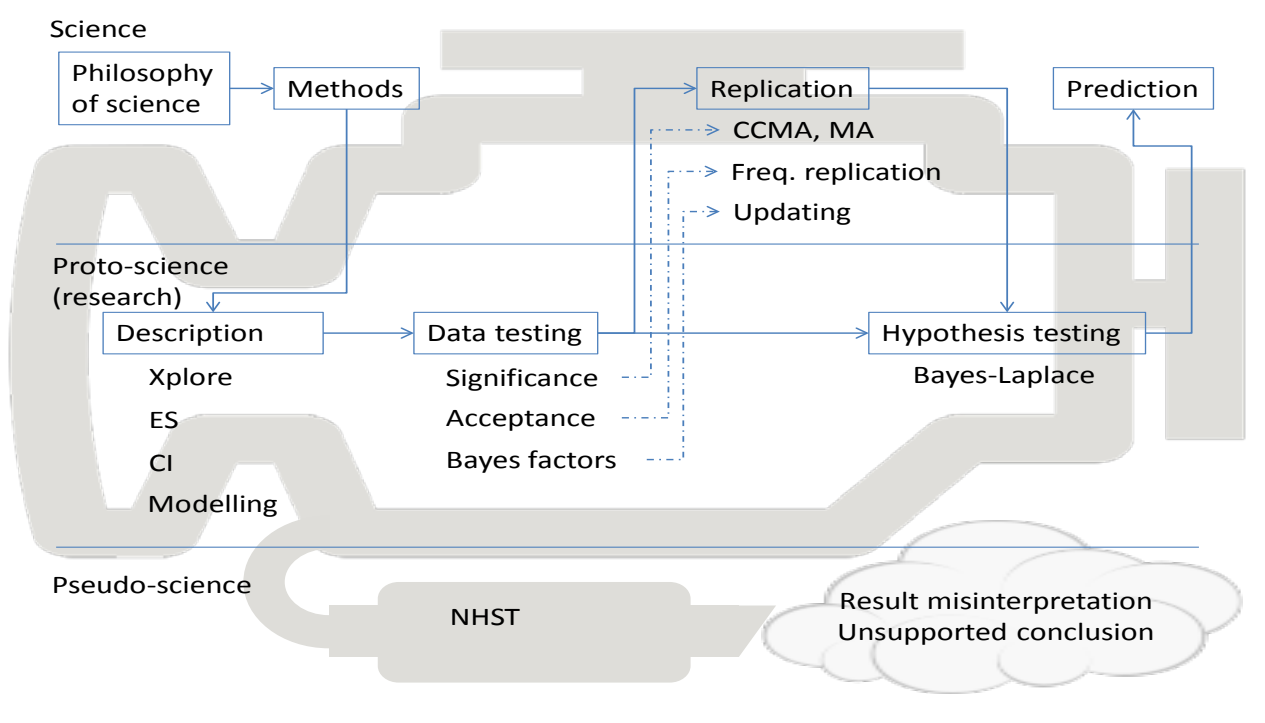

Figure 1. The engine of science

From Methodology, a large number of critics have faulted Benjamin et al.'s disregard of what is really affecting replication in order to focus on a relatively minor issue. Mayo, for example, lists biasing selection effects, cherry-picking, multiple testing, hunting for significance, optional stopping, violated statistical assumptions, missing or irrelevant statistical-substantive links, and questionable measurements as the main culprits in flawed findings and lack of reproducibility (2017a-e; also Gelman and McShane, 2017; Gelman, 2017b). Lakens et al. (2017) add lack of experimental redundancy, logical traps, research opacity, and poor accounting of sources of error, as well as the risks of reduced generalisability and research breadth were Benjamin et al.'s proposal to succeed. Methodological concerns were also raised by Young (2017), Passin (2017), Chapman (2017), Llewelyn (2017), Byrd (2017), Greenland (2017), Lew (2017), Steltenpohl (2017), McShane et al. (2017), Ferreira and Henderson (2017), Kong (2017) , Amrhein and Greenland (2017), Black (2017), Martin (2017], Hamlin (2017), Zollman (2017), Trafimow et al. (2017), Crane (2017), and Morey (2017). Some researchers even propose the use of preregistration as a way of minimizing above problems (Llewelyn, 2017; Hamlin, 2017; van der Zee, 2017) 
The pseudoscientific NHST element is the cornerstone of Benjamin et al.'s proposal, as it mixes Fisher's tests of significance with Neyman-Pearson's alternative hypotheses, Type II errors and power estimation, and with Bayesian prior probabilities, in order to argue about the false positive rate as the culprit for the lack of replicability. Indeed, the false positive rate argument has been heavily criticized by several authors: Mayo (2017b; also Byrd, 2017) chiefly derides as questionable the prior probabilities given to the hypotheses; Colquhoun (2017) denounces the credibility of Benjamin et al.'s false positive rate calculation for some of the prior probabilities used, which he sees as a rather liberal rate; Chapman (2017; also Byrd, 2017) claims that the prior probability ratios for the hypotheses are not realistic; Llewelyn (2017) raises an argument on prior probabilities and their combination with accumulated evidence in order to estimate the probability of future replication, not finding a more restrictive level of significance an adequate antecedent for increasing such probability; Krueger (2017) adds that, under the new proposal, the proportion of false negatives rises faster than the speed at which false positives drops, leading Phaf (2017) to wonder whether, because of it, "it makes more sense to increase, rather than reduce, the significance level for novel findings"; Kong (2017) states that the false positive rate formula is misleading and finds the expected false positive rate when testing the conventional $5 \%$ threshold.

Furthermore, Perezgonzalez (2017) argued that the misinterpretation of $p$-values as evidence in favour or against a hypothesis has more to do with the pseudoscientific use of NHST than with frequentist testing proper (also Mayo, 2017b; McShane et al., 2017; Amrhein and Greenland, 2017). As Benjamin et al.'s proposal is made within the pseudo-philosophical argument of NHST (e.g., confusing statistical and substantive significance; Mayo, 2017c), a lower threshold of significance does not improve such 'magical thinking' (also Greenland, 2017; Argamon, 2017; Krueger, 2017; Diebold, 2017; Phaf, 2017). Lakens et al. (2017; also O'Rourke, 2017; Morey, 2017) equally warn that the proposal exaggerates the focus on single $p$-values in scientific practice, education, decision making and publication.

Unsupported conclusions are other consequence of pseudoscientific thinking, and McShane et al. (2017) and Amrhein and Greenland (2017) highlight the risks of studies published under the new banner exaggerating effect sizes and overconfidence in significant results while discounting nonsignificant findings. De Brigard (2017) argues, instead, for the need to be humbler and not generalize to populations, irrespective of statistical significance, effects that may only be present in the sample.

The descriptive data analysis element was briefly touched upon by Mayo (2017a) - who recommends abandoning significance testing in favour of inferring the magnitudes that are well (or poorly) indicated by the data (a.k.a., Cls) - and Lew (2017), Phaf (2017), and McShane et al. (2017) whom argue for the need to interpret evidence in the context of other findings and theoretical models in lieu of NHST.

Regarding data testing, Mayo (2017a,b) and Perezgonzalez (2017) have no particular problem with a lower level of significance although both reckon Benjamin et al.'s proposal does not address anything in particular with frequentist testing proper. Mayo equally sees such lowering unnecessary as "you might not want to be too demanding before claiming evidence of a [null] model violation" (2017b), while the "lack of replication is effectively uncovered thanks to statistical significance tests" (2017e). Young (2017) reminds us of the appropriate use of significance tests in experimental contexts. McShane et al. (2017) also argues the credibility of uniformly most powerful priors and 
tests and the loss of its connection to Bayesianism as for justifying Benjamin et al.'s proposal (but see Wagenkamers and Gronau's counter-argument, 2017).

Other authors recommend continuing using $p$-values either as part of frequentist tests proper (Bates, 2017) or without significance testing, the latter including Mayo (2017b), Colquhoun (2017, who also proposes estimating false positive rates), Greenland (2017, who proposes transforming them to bits of information against the null hypothesis), Funder (2017), Diebold (2017), Lakens et al. (2017, who recommend justifying whatever thresholds may be used at the design stage), McShane et al. (2017, who recommend using them as descriptives among other neglected factors-but see Wagenkamers and Gronau's, 2017, counter-argument, and Gelman's, 2017a, counter-counter-argument), and Amrhein and Greenland (2017). Argamon (2017) suggests substituting Bayesian statistics, instead.

Addressing replication directly, Chapman (2017) and Trafimow et al. (2017) point out that the problem with replication is not too many false positives but insufficient power. Krueger (2017; also McShane et al., 2017, Trafimov et al., 2017) chides Benjamin et al. for the incoherence of considering replication as order-dependent and inverting the exploratory-confirmatory nature of replication by proposing to make the former more difficult to achieve and the latter more liberal. He further chides them on whether they would disallow their own past findings at the $5 \%$ threshold. Lakens et al. (2017; also Crane, 2017) found biases in the analyses done by Benjamin et al., and conclude that there is no [Bayesian] evidence that a lower level of significance improves replicability. They also warn of the risks of fewer availability of replication studies were the proposal to succeed (also Greenland, 2017). Roberts (2017), Kong (2017), Ickes (2017), Hamlin (2017), Gelman (2017b), and Trafimov et al. (2017) propose to stop the proverbial beating around the bushes and perform direct replications as a straightforward measure of replicability.

The hypothesis testing element (namely full Bayesian hypothesis testing) has been seldom touched upon but briefly by Llewelyn (2017), who extended the need for prior probabilities and even more accumulated evidence as pre-requisite for estimating the probability of hypotheses being 'true'.

In conclusion, despite Benjamin et al.'s best intentions, their proposal only reinforces the NHST pseudoscientific approach with a stricter bright-line threshold for claiming evidence it cannot possibly claim-irrespective of how well it calibrates with Bayes factors under certain conditionswhile dismissing potential consequences such as the stifling of research and its publication, an increase in false negatives, an increase in misbehaviour, and a continuation of pseudoscientific practices. Furthermore, theirs is a frequentist solution many of their Bayesian proponents do not even believe in, born out of a false belief of lacking equally simple but better-suited alternatives (Machery, 2017).

In reality, an equally simple and better suited alternative exists, perhaps the only one the authors could be entitled to make from their Jeffresian perspective, hence our own recommendation: Use JASP, the stand-alone, free-to-download, R-based statistical software with user-friendly interface, developed by Wagenmakers' team (https://jasp-stats.org). JASP allows for analysing the same dataset using frequentist (Fisher's tests of significance) and Bayesian tools (Jeffreys's Bayes factors) without necessarily forcing a mishmash of philosophies of science. JASP allows for the Popperian (also Meehl's, Mayo's) approach to severely testing a null hypothesis but also to ascertain the credibility of tests based on the observed data. JASP allows researchers to qualitatively calibrate their significance tests to Bayes factors but also the possibility of calibrating Bayes factors to 
frequentist tests so as to ascertain their error probabilities. JASP is an existing simple and easy application that shows two interpretations of the same data, which aligns well with the training undertaken by frequentist and Jeffreysian researchers alike while allowing them the opportunity to learn the alternative philosophy-irrespective of which they will choose for publication-and may as well help diminish the misinterpretation of results and the reaching of unsupported conclusions. In so doing, it may even help improve replicability.

\section{References}

Amrhein, V., and Greenland, S. (2017, September 25). Remove, rather than redefine, statistical significance. Nature Hum. Behav. doi: 10.1038/s41562-017-0224-0

Argamon, S. E. (2017, July 26). New "p < 0.005" standard considered harmful [Web log post]. Retrieved from http://multaverba.blogspot.co.nz/2017/07/new-p-0005-standard-consideredharmful.html

Bates, T. (2017, July 23). Changing the default p-value threshold for statistical significance ought not be done, and is the least of our problems [Web log post]. Retrieved from https://medium.com/@timothycbates/changing-the-default-p-value-threshold-for-statisticalsignificance-ought-not-be-done-in-isolation-3a7ab357b5c1

Benjamin, D. J., Berger, J. O., Johannesson, M., Nosek, B. A., Wagenkamers, E. J., Berk, R., . . Johnson, V. E. (2017a, July 22). Redefine statistical significance. Retrieved from https://osf.io/preprints/psyarxiv/mky9j

Benjamin, D. J., Berger, J. O., Johannesson, M., Nosek, B. A., Wagenkamers, E. J., Berk, R., . . Johnson, V. E. (2017b, September 1). Redefine statistical significance. Nature Hum. Behav. 1, 0189. doi: 10.1038/s41562-017-0189-z

Black, J. (2017, September 27). Thresholds [Web log comment]. Retrieved from https://funderstorms.wordpress.com/2017/07/26/thresholds

Byrd, J. (2017, July 28-31). "A megateam of reproducibility-minded scientists" look to lowering the p-value [Web log comment]. Retrieved from https://errorstatistics.com/2017/07/25/a-megateamof-reproducibility-minded-scientists-look-to-lowering-the-p-value

Chapman, P. (2017, July 27). "A megateam of reproducibility-minded scientists" look to lowering the p-value [Web log comment]. Retrieved from https://errorstatistics.com/2017/07/25/a-megateamof-reproducibility-minded-scientists-look-to-lowering-the-p-value

Colquhoun, D. (2017, July 26). "A megateam of reproducibility-minded scientists" look to lowering the $p$-value [Web log comment]. Retrieved from https://errorstatistics.com/2017/07/25/amegateam-of-reproducibility-minded-scientists-look-to-lowering-the-p-value

Crane, H. (2017). Why "Redefining Statistical Significance" will not improve reproducibility and could make the replication crisis worse. PsyArXiv Preprints. doi: 10.17605/OSF.IO/BP2Z4 
De Brigard, F. (2017, October 2). Should we redefine statistical significance. A brains blog roundatble [Web log comment]. Retrieved from http://philosophyofbrains.com/2017/10/02/should-weredefine-statistical-significance-a-brains-blog-roundtable.aspx

Diebold, F. X. (2017, August 27). New p-value thresholds for statistical significance [Web log post]. Retrieved from https://fxdiebold.blogspot.co.nz/2017/08/new-p-value-thresholds-forstatistical.html

Easwaran, K. (2017, October 2). Should we redefine statistical significance. A brains blog roundatble [Web log comment]. Retrieved from http://philosophyofbrains.com/2017/10/02/should-weredefine-statistical-significance-a-brains-blog-roundtable.aspx

Ferreira, F., and Henderson, J. M. (2017, July 26). Defending .05: It's not enough to be suggestive [Web log post]. Retrieved from https://rolfzwaan.blogspot.co.nz/2017/07/defending-05-its-notenough-to-be_26.html

Funder, D. (2017, July 26). Thresholds [Web log post]. Retrieved from https://funderstorms.wordpress.com/2017/07/26/thresholds

Gelman, A. (2017a, October 2). Response to some comments on "Abandon Statistical Significance" [Web log post]. Retrieved from http://andrewgelman.com/2017/10/02/response-commentsabandon-statistical-significance

Gelman, A. (2017b, October 3). When considering proposals for redefining or abandoning statistical significance, remember that their effects on science will only be indirect! [Web log post]. Retrieved from http://andrewgelman.com/2017/10/03/one-discussion-redefining-abandoning-statisticalsignificance

Gelman, A., and McShane, B. (2017, October 2). Should we redefine statistical significance. A brains blog roundatble [Web log comment]. Retrieved from http://philosophyofbrains.com/2017/10/02/should-we-redefine-statistical-significance-a-brainsblog-roundtable.aspx

Greenland, S. (2017, July 30-31). "A megateam of reproducibility-minded scientists" look to lowering the p-value [Web log comment]. Retrieved from https://errorstatistics.com/2017/07/25/amegateam-of-reproducibility-minded-scientists-look-to-lowering-the-p-value

Greenland, S., Senn, S. J., Rothman, K. J., Carlin, J. B., Poole, C., Goodman, S. N., and Altman, D. G. (2016). Statistical tests, $p$ values, confidence intervals, and power: a guide to misinterpretations. Eur J Epidemiol 31, 337-350. doi: 10.1007/s10654-016-0149-3

Hamlin, K. (2017, October 2). Should we redefine statistical significance? A brains blog roundtable [Web log comment]. Retrieved from http://philosophyofbrains.com/2017/10/02/should-weredefine-statistical-significance-a-brains-blog-roundtable.aspx

Ickes, W. (2017, September 27). Thresholds [Web log comment]. Retrieved from https://funderstorms.wordpress.com/2017/07/26/thresholds

Kong, X. (2017, September 21). Redefine statistical significance? Let's just do science in a scientific way [Web log post]. Retrieved from http://conxz.net/2017/09/21/redefine-significance 
Krueger, J. I. (2017, July 30). Fear of false positives [Web log post]. Retrieved from https://www.psychologytoday.com/blog/one-among-many/201707/fear-false-positives

Lakens, D., Adolfi, F. G., Albers, C. J., Anvari, F., Apps, M. A. J., Argamon, S. E., . . Zwaan, R. A. (2017). Justify your alpha: A response to "Redefine statistical significance". Retrieved from https://psyarxiv.com/9s3y6

Lew, M. (2017, July 27ss). "A megateam of reproducibility-minded scientists" look to lowering the pvalue [Web log comment]. Retrieved from https://errorstatistics.com/2017/07/25/a-megateam-ofreproducibility-minded-scientists-look-to-lowering-the-p-value

Llewelyn, H. (2017, July 27). "A megateam of reproducibility-minded scientists" look to lowering the p-value [Web log comment]. Retrieved from https://errorstatistics.com/2017/07/25/a-megateamof-reproducibility-minded-scientists-look-to-lowering-the-p-value

Machery, E. (2017, October 2). Should we redefine statistical significance. A brains blog roundatble [Web log comment]. Retrieved from http://philosophyofbrains.com/2017/10/02/should-weredefine-statistical-significance-a-brains-blog-roundtable.aspx

Martin, S. (2017, October 2). Response to some comments on "Abandon Statistical Significance" [Web log comment]. Retrieved from http://andrewgelman.com/2017/10/02/response-commentsabandon-statistical-significance

Mayo, D. (2017a, July 25). "A megateam of reproducibility-minded scientists" look to lowering the pvalue [Web log post]. Retrieved from https://errorstatistics.com/2017/07/25/a-megateam-ofreproducibility-minded-scientists-look-to-lowering-the-p-value

Mayo, D. (2017b, July 25ss). "A megateam of reproducibility-minded scientists" look to lowering the p-value [Web log comment]. Retrieved from https://errorstatistics.com/2017/07/25/a-megateamof-reproducibility-minded-scientists-look-to-lowering-the-p-value

Mayo, D. (2017c, October 2). Should we redefine statistical significance? A brains blog roundtable [Web log comment]. Retrieved from http://philosophyofbrains.com/2017/10/02/should-weredefine-statistical-significance-a-brains-blog-roundtable.aspx

Mayo, D. (2017d, October 5). New venues for the statistics wars [Web log post]. Retrieved from https://errorstatistics.com/2017/10/05/new-venues-for-the-statistics-wars

Mayo, D. (2017e, October 26). Going round and round again: a roundtable on reproducibility \& lowering p-values [Web log post]. Retrieved from https://errorstatistics.com/2017/10/26/goinground-and-round-again-a-roundtable-on-reproducibility-lowering-p-values

Morey, R. D. (2017, November 27). When the statistical tail wags the scientific dog [Web log post]. Retrieved from https://medium.com/@richarddmorey/when-the-statistical-tail-wags-the-scientificdog-d09a9f1a7c63

McShane, B. B., Gal, D., Gelman, A., Robert, C., and Tackett, J. L. (2017). Abandon statistical significance. Retrieved from https://arxiv.org/abs/1709.07588

O'Rourke, K. (2017b, July 31). "A megateam of reproducibility-minded scientists" look to lowering the p-value [Web log comment]. Retrieved from https://errorstatistics.com/2017/07/25/amegateam-of-reproducibility-minded-scientists-look-to-lowering-the-p-value 
Phaf, R. H. (2017, August 30). Comment on redefine statistical significance [Web log post]. Retrieved from http://commentsonscientificmatters.blogspot.co.nz

Passin, T. (2017, July 25). "A megateam of reproducibility-minded scientists" look to lowering the pvalue [Web log comment]. Retrieved from https://errorstatistics.com/2017/07/25/a-megateam-ofreproducibility-minded-scientists-look-to-lowering-the-p-value

Perezgonzalez, J.D. (2017, July 27). Better Science - The call for significance of 5\% (0.005) [Video file]. Retrieved from https://youtu.be/Al3Zs7Bwc8U

Resnick, B. (2017, July 31). What a nerdy debate about $p$-values shows about science - and how to fix it [Web log post]. Retrieved from https://www.vox.com/science-andhealth/2017/7/31/16021654/p-values-statistical-significance-redefine-0005

Roberts, B. (2017, July 28). Thresholds [Web log comment]. Retrieved from https://funderstorms.wordpress.com/2017/07/26/thresholds

Savehn, T. (2017, August 1). "A megateam of reproducibility-minded scientists" look to lowering the p-value [Web log comment]. Retrieved from https://errorstatistics.com/2017/07/25/a-megateamof-reproducibility-minded-scientists-look-to-lowering-the-p-value

Steltenpohl, C. N. (2017, September 18). The littlest p: redefining statistical significance [Web log post]. Retrieved from http://www.crystalns.com/littlest-p-statistical-significance

Trafimow, D., Amrhein, V., Areshenkoff, C. N., Barrera-Causil, C., Beh, E. J., Bilgiç, Y., . . . Marmolejo-Ramos, F. (2017, November 14). Manipulating the alpha level cannot cure significance testing. Comments on "Redefine statistical significance". PeerJ Preprints 5:e3411v1. doi: 10.7287/peerj.preprints.3411v1

van der Zee, T. (2017, November 23). Arguing for all the wrong reforms [Web log post]. Retrieved from http://www.timvanderzee.com/arguing-wrong-reforms

Wagenmakers, E.J. (2017, August 3). Redefine statistical significance Part I: Sleep trolls \& red herrings [Web log post]. Retrieved from https://www.bayesianspectacles.org/redefine-statisticalsignificance-part-i-sleep-trolls-red-herrings

Wagenmakers, E.J., and Gronau, Q. (2017, September 29). Redefine statistical significance Part IX: Gelman and Robert join the fray, but are quickly chased by two kangaroos [Web log post]. Retrieved from https://www.bayesianspectacles.org/redefine-statistical-significance-part-ix-gelman-androbert-join-the-fray-but-are-quickly-chased-by-two-kangaroos

Young, S. (2017, July 25). "A megateam of reproducibility-minded scientists" look to lowering the pvalue [Web log comment]. Retrieved from https://errorstatistics.com/2017/07/25/a-megateam-ofreproducibility-minded-scientists-look-to-lowering-the-p-value/

Zollman, K. (2017, October 2). Should we redefine statistical significance? A brains blog roundtable [Web log comment]. Retrieved from http://philosophyofbrains.com/2017/10/02/should-weredefine-statistical-significance-a-brains-blog-roundtable.aspx 